\title{
Antiallergic and Antiarthritic Effects of Stem Bark Extract of Glyphaea brevis (Spreng) Monachino (Tiliaceae) in Murine Models
}

\author{
David D. Obiri, Newman Osafo, and Regina E. Abotsi \\ Department of Pharmacology, Faculty of Pharmacy and Pharmaceutical Sciences, College of Health Sciences, \\ Kwame Nkrumah University of Science and Technology, Kumasi, Ghana \\ Correspondence should be addressed to David D. Obiri; ddobiri.pharm@knust.edu.gh
}

Received 22 July 2013; Accepted 13 August 2013

Academic Editors: P. Cos and T. W. Stone

Copyright (C) 2013 David D. Obiri et al. This is an open access article distributed under the Creative Commons Attribution License, which permits unrestricted use, distribution, and reproduction in any medium, provided the original work is properly cited.

\begin{abstract}
Background. Various parts of Glyphaea brevis (Spreng) Monachino (Tiliaceae) find a use in traditional medicine in the treatment of pain and oedema among others. This study evaluates the anti-inflammatory, antiallergic, and antiarthritic effects of a 70\% (v/v) aqueous ethanol extract of the stem bark of Glyphaea brevis in murine models. Materials and Methods. The effect of the aqueous ethanol extract of Glyphaea brevis extract (GBE) was assessed on the maximal and total oedema responses in the carrageenaninduced paw oedema in mice to evaluate the acute anti-inflammatory actions of the extract. Systemic anaphylaxis was induced with compound $48 / 80$ and survival rates monitored for $1 \mathrm{~h}$ in mice with prior treatment with GBE to assess the anti-allergic action of the extract. The indirect antihistamine effect of GBE was evaluated on clonidine-induced catalepsy. Rat adjuvant-induced arthritis model was used to study GBE's antiarthritic action. Results. GBE significantly suppressed the mean maximal swelling and the total paw swellings over $6 \mathrm{~h}$ in the carrageenan-induced paw oedema when administered either prophylactically or therapeutically. GBE dose dependently increased the time for compound 48/80-induced mortality. Administered either prophylactically or therapeutically, GBE inhibited clonidine-induced catalepsy while it had no effect on haloperidol-induced catalepsy. GBE caused a significant dose-dependent suppression of Freund's adjuvant-induced arthritis. Conclusion. Glyphaea brevis inhibits the in vivo degranulation of mast cells and thereby suppress allergy. In addition it exhibits anti-inflammatory action and attenuates Freund's adjuvant-induced arthritis. The results of this work contribute to validate the traditional use of Glyphaea brevis in the management of inflammatory disorders.
\end{abstract}

\section{Introduction}

Anaphylaxis is a rapid, life-threatening allergic reaction often triggered by food, drugs, insect venoms, latex, or allergen immunotherapy [1-5]. This acute allergic response is mediated by mast cells and basophils [6]. Mast cells express as one of their surface receptors the high affinity receptor for immunoglobulin E, IgE (FceRI) [7] and play a central role in the inflammatory and immediate-type allergic responses that occur when sensitised individuals contact allergen through body surfaces [8]. In the absence of an antigen, the FceRI binds to IgE. The major mechanism for the activation of these cells is the interaction of an antigen with the IgEbound FceRI. An alternative pathway of activation of the mast cell is offered by the so-called peptidergic pathway, a nonimmunologic mechanism. This is achieved by basic secretagogues of mast cells [9] which are polycationic and include compound 48/80. Stimulation of mast cells with IgE or compound $48 / 80$ triggers the activation of signal transduction pathways which initiates a complex series of biochemical events leading to the release of mediators that cause allergic inflammation and anaphylactic reactions and delayed chronic inflammation [10-12]. One such chronic inflammatory disease is adjuvant-induced arthritis (AA) in rats which is characterized by infiltration of synovial membrane in association with destruction of joint and closely resembles rheumatoid arthritis in humans [13] as antibody to Mycobacterial antigen is reported in AA and also in rheumatoid arthritis.

The most commonly prescribed medication for the treatment of both acute and chronic inflammatory disorders 
such as allergy and rheumatoid arthritis, respectively, includes antihistamines, steroidal (glucocorticoids), nonsteroidal anti-inflammatory drugs (NSAIDs), disease-modifying antirheumatic (DMARDs) and immunosuppressant drugs. Primarily, though the goal of these drugs has been to relieve inflammation, prevent joint destruction, relieve pain, and to restore function of disabled joints, they are known to produce various side effects including gastrointestinal disorders, immunodeficiency, humoral disturbances, and even life-threatening effects [14-16]. In addition very recent findings have shown that glucocorticoids, the most potent anti-inflammatory drugs, are ineffective in anaphylaxis [17] or effective only when combined with a phosphatase inhibitor [18]. Consequently, the search for new potent regimens with less or no side effects especially from plant sources is heightened. In this regard, clinical benefits obtained with extracts from Berberis, Tripterygium, and Urtica species for treating rheumatic diseases are worth noting [19-21].

Glyphaea brevis is among the plants with potential anti-inflammatory actions used in traditional medicine in Ghana. Indeed, Dickson et al. have documented the antiinflammatory action of G. brevis in the carrageenan-induced paw oedema in 7-day old cockerels [22]. Glyphaea brevis (Spreng) Monachino (family Tiliaceae) is a tree mainly present in forest regrowth, swampy places, rocky savanna, forest galleries, and fallow land. Different parts of the plant from the leaves through the stem bark to the roots have found a use in the traditional treatment of several disorders including chest pain and hepatitis and as an anticonvulsant [23-26]. Biological screen reveals that the leaves have antimicrobial [27] and antioxidant effects [28]. Phytochemical screening has shown the presence of cardiac glycosides, flavonoids, saponins, terpenoids, and tannins but no alkaloids [29]. Mbosso et al. identify linear long-chain aliphatic compounds, triterpenes, and steroids [30] as constituents.

In the current study, we demonstrate that the aqueous ethanol extract of Glyphaea brevis has inhibitory effects on the carrageenan-induced inflammation in mice. We subsequently show that Glyphaea brevis has suppressant effects on experimental immediate allergic reactions and also exhibits antiarthritic actions in mice and rats, respectively.

\section{Materials and Methods}

2.1. Collection of Plant Material. The stem bark of Glyphaea brevis was collected from the campus of the Forestry Research Institute of Ghana (FORIG) of the Council for Scientific and Industrial Research (CSIR), Fumesua, in January, 2012. The plant was authenticated by anatomical observation and direct comparison with the authentic specimens by A. Y. Yeboah-Mensah (Ph.D.) of the Department of Pharmacognosy, KNUST, and a specimen voucher GBE/T/010712 kept at the Department's herbarium.

2.2. Preparation of Plant Extract. The stem bark was air dried at room temperature chopped and milled into powder with a heavy duty blender (model 37BL85 (240CB6), Waring Commercial, USA). $2.0 \mathrm{~kg}$ of the powdered plant material was extracted by cold percolation with $4 \mathrm{~L}$ of $70 \% \mathrm{v} / \mathrm{v}$ ethanol for 5 days. The ethanol filtrate was concentrated under reduced pressure at $45^{\circ} \mathrm{C}$ by a vacuum rotary evaporator (model R-210, BUCHI, Switzerland) and further dried in an oven (Gallenkamp OMT, SANYO, Japan) to yield a solid mass of weight $107 \mathrm{~g}$. The dried extract freshly dissolved in normal saline was referred to as GBE and was orally administered to experimental animals.

2.3. Animals. C57BL/6 and ICR mice (25-30 g) of both sexes and male Sprague-Dawley rats (180-200 g) were purchased from Noguchi Memorial Institute for Medical Research, University of Ghana, Accra, Ghana. The animals were kept in the Animal House of the Department of Pharmacology, College of Health Sciences, KNUST, Kumasi, Ghana, and allowed to acclimatize to the laboratory conditions (temperature $23 \pm 2^{\circ} \mathrm{C}$ with a 12-hour light-dark cycle) for 14 days. Animals had free access to commercial pellet diet (GAFCO, Ghana) and water ad libitum. At the end of each experiment all animals used were euthanized ensuring that each animal was therefore used only once throughout the study. As per the internationally accepted principles for laboratory animal use and care (EEC Directive of 1986: $86 / 609$ EEC), the animals were humanely handled throughout the experiment. Additionally all animal experiments were approved by the Department of Pharmacology, KNUST Ethics Committee (D/COL/GBE/2012 dated 24/02/2012).

2.4. Chemicals and Reagents. Compound 48/80 (C2313), $\lambda$-Carrageenan, and aspirin were purchased from SigmaAldrich (St Louis, USA). Clonidine was purchased from Boehringer Ingelheim Inc. (USA). Haloperidol was obtained from Janssen-Cilag Pty Ltd. (UK). Chlorpheniramine was supplied by DWD Pharmaceuticals Ltd. (India). Diclofenac and Liquid Paraffin were supplied by Troge (Germany) and Actavis Ltd. (UK), respectively.

2.5. Microorganism. Heat-killed Mycobacterium tuberculosis (strains C, DT, and PN (mixed)) was a kind donation from the Ministry of Agriculture, Fisheries and Food, UK.

2.6. Preparation of the Adjuvant. $20 \mathrm{mg}$ of heat-killed Mycobacterium tuberculosis (strains C, DT, and PN (mixed)) was finely ground in a mortar. Enough sterile liquid paraffin was added and triturated to $5 \mathrm{mg} \mathrm{mL}^{-1}$ suspension referred to as the Complete Freund Adjuvant, CFA. Sterile liquid paraffin only constitutes the Incomplete Freund Adjuvant, IFA.

\subsection{Acute Anti-Inflammatory Study}

2.7.1. Induction of Carrageenan Paw Oedema. As earlier described by Winter et al., paw oedema was induced by injection of a $1 \%$ carrageenan suspension in normal saline $(50 \mu \mathrm{L}$, s.c.) into the subplantar tissue of the right hind paw of ICR mice $(25-30 \mathrm{~g})$ [31]. Oedema was monitored at $1 \mathrm{~h}$ intervals over $6 \mathrm{~h}$ with an electronic calliper (model Z22855, Milomex Ltd., Bedfordshire, UK) and expressed as the mean 
change in paw thickness. To determine the mean percent increase in paw thickness for each treatment, the following equation was used:

$$
\% \text { increase in paw thickness }=\left[\frac{D_{t}-D_{0}}{D_{0}}\right] \times 100,
$$

where $D_{0}$ and $D_{t}$ are, respectively, the paw thickness before and at time $T$ of the induction of the oedema.

Total oedema induced during the $6 \mathrm{~h}$ was determined as the area under the time course curves (AUC). To determine the percent inhibition of the total oedema for each treatment, the following equation was used:

$\%$ inhibition of oedema

$$
=\left[\frac{\mathrm{AUC}(\text { control })-\mathrm{AUC}(\text { drug treatment })}{\mathrm{AUC}(\text { control })}\right] \times 100 \text {. }
$$

Drug effects were evaluated by comparing the maximal and total oedema responses attained during $6 \mathrm{~h}$ in drug-treated groups with the corresponding values attained in salinetreated inflamed control groups. In the preventive (prophylactic) protocol, drug-vehicle, GBE 30, 100, and $300 \mathrm{mg} \mathrm{kg}^{-1}$, and aspirin $100 \mathrm{mg} \mathrm{kg}^{-1}$ was given orally $1 \mathrm{~h}$ prior to the induction of the oedema while, in the curative (therapeutic) protocol, treatment was done $1 \mathrm{~h}$ after oedema induction.

\subsubsection{Antianaphylactic Study}

Compound 48/80-Induced Systemic Anaphylaxis. C57BL/6 mice $(25-30 \mathrm{~g})$ were given an i.p. injection of $10 \mathrm{mg} \mathrm{kg}^{-1}$ of the mast cell degranulator compound $48 / 80$ to induce systemic anaphylaxis as previously described by Kim et al. [32]. Either drug-vehicle or GBE 30, 100, and $300 \mathrm{mg} \mathrm{kg}^{-1}$ was given orally $1 \mathrm{~h}$ prior to administration of compound $48 / 80$. Mortality was monitored for $1 \mathrm{~h}$ after induction of anaphylaxis.

\subsection{Indirect Antihistamine Effect}

2.8.1. Induction of Clonidine Catalepsy. As earlier described by Ferre et al., clonidine $\left(1 \mathrm{mg} \cdot \mathrm{kg}^{-1}\right.$, s.c.) was administered to $8-10$-week-old ICR mice $(20-25 \mathrm{~g})$ in the bar test [33]. To test for catalepsy, rats were positioned so that their hindquarters were on the bench and their forelimbs rested on a $1 \mathrm{~cm}$ diameter horizontal bar, $10 \mathrm{~cm}$ above the bench. The time required to remove the paws from the bar was noted for each animal. The duration of catalepsy was measured at $30 \mathrm{~min}$ intervals up to $180 \mathrm{~min}$ after administration of clonidine. In the preventive (prophylactic) protocol, drugvehicle $\left(5 \mathrm{~mL} \mathrm{~kg}^{-1}\right), \mathrm{GBE} 30,100$, and $300 \mathrm{mg} \mathrm{kg}^{-1}$, and chlorpheniramine $\left(10 \mathrm{mg} \mathrm{kg}^{-1}\right)$ was given orally for 2 consecutive days ending 30 min before clonidine injection while, in the curative (therapeutic) protocol, treatment was done $60 \mathrm{~min}$ after catalepsy induction.
2.8.2. Induction of Haloperidol Catalepsy. The same bar test, as earlier described by Ferre et al., was employed [33]. Haloperidol ( $1 \mathrm{mg} \cdot \mathrm{kg}^{-1}$, s.c.) was administered to 8-10week-old ICR mice (20-25 g). The duration of catalepsy was measured at $30 \mathrm{~min}$ intervals up to $180 \mathrm{~min}$ after administration of haloperidol. Drug-vehicle $\left(5 \mathrm{~mL} \mathrm{~kg}^{-1}\right), \mathrm{GBE}(30$, 100 , and $\left.300 \mathrm{mg} \mathrm{kg}^{-1}\right)$, and chlorpheniramine $\left(10 \mathrm{mg} \mathrm{kg}^{-1}\right)$ were given orally for 2 consecutive days ending $30 \mathrm{~min}$ before haloperidol injection.

\subsection{Chronic Anti-Inflammatory Study}

2.9.1. Induction of Rat Adjuvant Arthritis. Adjuvant arthritis was induced as previously described by Pearson. Briefly, the right hind paw of Sprague-Dawley rats (200-250 g) was injected intraplantar with $100 \mu \mathrm{L}$ of Complete Freund's Adjuvant (CFA) [34]. Arthritic control group received intraplantar injection of CFA, while nonarthritic control group received only intraplantar injection of $100 \mu \mathrm{L}$ sterile paraffin oil (Incomplete Freund's Adjuvant, IFA). Foot volume was measured by water displacement method with a plethysmometer (model 7140, Ugo Basile, Italy) as described by Fereidoni et al. [35] for the ipsilateral (injected) and contralateral (noninjected) hind limbs prior to intraplantar injection of CFA/IFA and daily for 28 days. The oedema component of inflammation was quantified by measuring the difference in foot volume between day zero and the various time points. Foot volumes were individually normalized as percentage of change from their values at day zero and then averaged for each treatment group. To determine the mean percent change in paw volume for each treatment, the following equation was used:

$$
\% \text { change in paw volume }=\left[\frac{V_{t}-V_{0}}{V_{0}}\right] \times 100,
$$

where $V_{0}$ and $V_{t}$ are, respectively, the paw volumes before and at time $T$ of the induction of the arthritis.

Total oedema induced during the acute phase (day 010) and polyarthritic phase (day 0-28) was determined as area under the time course curves (AUC). To determine the percent inhibition of the total oedema for each treatment, the following equation was used:

$\%$ inhibition of oedema

$$
=\left[\frac{\mathrm{AUC}(\text { control })-\mathrm{AUC}(\text { drug treatment })}{\mathrm{AUC}(\text { control })}\right] \times 100 \text {. }
$$

Drug effects were evaluated by comparing the maximal and total oedema responses attained during 28 days in drugtreated groups with the corresponding values attained in saline-treated inflamed control groups. In the preventive (prophylactic) protocol, drug-vehicle, GBE 30, 100, and $300 \mathrm{mg} \mathrm{kg}^{-1}$, and diclofenac $6 \mathrm{mg} \mathrm{kg}^{-1}$, was given orally $1 \mathrm{~h}$ before the induction of the oedema on day zero and daily for 28 days while, in the curative (therapeutic) protocol, treatment was commenced on day 10 after oedema induction 
till day 28. All drugs were freshly prepared on each day of drug administration.

2.10. Statistical Analysis. All data were reported as mean values \pm standard error of mean (s.e.m), $n=5$. Timecourse curves where appropriate were subjected to two-way (treatment $\times$ time) repetitive measures analysis of variance (ANOVA) with Bonferroni's post hoc test. Differences in AUCs were analysed by a one-way ANOVA followed by a Student-Neuman-Keul's range test. In case of the lethality rate, the Kaplan-Meier Survival plots were used. Differences were considered significant at $P \leq 0.05$. All graphs were plotted with GraphPad prism for Windows Version 5.00 (GraphPad, San Diego, CA, USA).

\section{Results}

3.1. Effect of G. brevis Extract (GBE) on Carrageenan-Induced Paw Oedema. As carrageenan-induced oedema culminates in degranulation involving the release of histamine and other autocoids from allergen-specific IgE-activated mast cells which mediate the initial phase of the acute inflammatory response, we examined the effect of GBE on acute inflammation in the mouse. To investigate the anti-inflammatory effect of $\mathrm{GBE}$, we injected $50 \mu \mathrm{L}$ of a $1 \%$ carrageenan suspension into subplantar tissue of the right hind paw of mice. Drug effects were evaluated by comparing the maximal and total oedema responses attained during $6 \mathrm{~h}$ in drug-treated groups with the corresponding values attained in the saline-treated control groups before and after the induction of the oedema. When administered before (preventive) the induction of the carrageenan paw oedema, $\operatorname{GBE}\left(30,100\right.$, and $\left.300 \mathrm{mg} \mathrm{kg}^{-1}\right)$ dose dependently caused the mean maximal swelling attained during 6 h to be significantly $(P \leq 0.0001)$ reduced, respectively, to $30.00 \pm 2.84 \%, 19.56 \pm 4.43 \%$, and $19.02 \pm 3.36 \%$ of the mean inflamed control response of $57.76 \pm 2.22 \%$ (Figure 1(a)). The total paw swellings induced over the $6 \mathrm{~h}$ (measured as the area under the time course curve, AUC) were also dose dependently and significantly $(P \leq 0.0001)$ suppressed, respectively, to $67.40 \pm 3.55 \%, 46.89 \pm 6.15 \%$, and $35.45 \pm 6.70 \%$ of the inflamed control response (Figure 1(b)) corresponding, respectively, to $32.60 \pm 4.33 \%, 53.11 \pm 6.63 \%$, and $64.55 \pm 7.15 \%$ inhibitions of the mean total oedema response. G. brevis administered in the same doses after the induction (curative) of the carrageenan paw oedema significantly $(P \leq 0.0002)$ suppressed the mean maximal swelling attained during the $6 \mathrm{~h}$, respectively, to $48.06 \pm 1.96 \%$, $43.62 \pm 1.10 \%$, and $37.24 \pm 2.18 \%$ of the mean inflamed control response of $57.76 \pm 2.22 \%$ (Figure $1(\mathrm{c})$ ). However, the total paw swellings induced over the $6 \mathrm{~h}$ were significantly suppressed, respectively, to $87.71 \pm 2.23 \%$ and $70.55 \pm$ $4.43 \%$ of the mean control response at 100 and $300 \mathrm{mg} \mathrm{kg}^{-1}$ (Figure 1(d)) corresponding, respectively, to $12.29 \pm 3.73 \%$ and $29.45 \pm 5.31 \%$ inhibitions of the total oedema response. Aspirin (100 mg kg ${ }^{-1}$ ), a positive control drug, significantly suppressed all the parameters under study (Figures 1(a)-1(d)).
3.2. Effect of G. brevis Extract (GBE) on Compound 48/80Induced Systemic Anaphylaxis. As allergen-induced degranulation of mast cell is a component of allergy and an extreme form of the allergic reaction is anaphylaxis, we investigated whether GBE exerts an inhibitory effect on anaphylaxis. To determine the effect of GBE on this allergic reaction, an in vivo model of a systemic reaction was used. Compound $48 / 80\left(10 \mathrm{mg} \mathrm{kg}^{-1}\right)$ was used as a model for induction of a systemic fatal allergic reaction. Injection of compound $48 / 80$ into mice induced fatal shock in $100 \%$ of animals in $10 \mathrm{~min}$. When administered $\left(30,100\right.$, and $\left.300 \mathrm{mg} \mathrm{kg}^{-1}\right)$ GBE caused the latent time for the death of mice injected with compound $48 / 80$ to be significantly and dose dependently increased to $12.5,18.25$, and $30 \mathrm{~min}$, respectively (Figure 2 ).

\subsection{Effect of $G$. brevis Extract (GBE) on Clonidine-Induced} Catalepsy. As histamine is frequently used as an indicator of mediator release in IgE-dependent immediate-type anaphylaxis, we studied the indirect antihistamine effect of the extract on histamine release from mast cells in clonidine-induced catalepsy. Catalepsy was induced in all the mice after the administration of clonidine $\left(1 \mathrm{mg} \mathrm{kg}^{-1}\right.$, s.c) and this peaked at $120 \mathrm{~min}$ in the vehicle-treated control group. $\operatorname{GBE}\left(30,100\right.$, and $\left.300 \mathrm{mg} \mathrm{kg}^{-1}\right)$ and chlorpheniramine $\left(10 \mathrm{mg} \mathrm{kg}^{-1}\right)$ showed significant dose-dependent inhibition of clonidine-induced catalepsy at all time points in the preventive protocol (Figure 3(a)). In the curative protocol, both chlorpheniramine and GBE significantly suppressed the clonidine-induced catalepsy from $120 \mathrm{~min}$ to $180 \mathrm{~min}$ (Figure 3(b)).

3.4. Effect of G. brevis Extract (GBE) on Haloperidol-Induced Catalepsy. As catalepsy can also be induced by neuroleptic drugs and is a common extrapyramidal side effect of drugs that either increase histamine release in the brain or inhibit dopaminergic transmission, we studied the effect of $G$. brevis on haloperidol-induced catalepsy in mice. Catalepsy was observed in all the groups peaking at $150 \mathrm{~min}$ in the vehicle control group after the administration of haloperidol $\left(1 \mathrm{mg} \mathrm{kg}^{-1}\right.$, s.c). GBE $\left(30,100\right.$, and $\left.300 \mathrm{mg} \mathrm{kg}^{-1}\right)$ and chlorpheniramine $\left(10 \mathrm{mg} \mathrm{kg}^{-1}\right)$ showed no significant inhibition of haloperidol-induced catalepsy at all time points studied (Figure 4).

3.5. Effect of G. brevis Extract (GBE) on Rat Adjuvant-Induced Arthritis. Since events of both carrageenan-induced oedema and the primary phase of adjuvant-induced arthritis correspond to those in the early exudative phase of inflammation which is an important feature of inflammatory pathology, we studied the effect of the extract on rat adjuvant-induced arthritis, a model of chronic inflammation. Adjuvant arthritis was induced in the right hind paw of rats with an intraplantar injection of CFA. Drug effects were evaluated by comparing the maximal and total oedema responses attained during 28 days in drug-treated groups with the corresponding values attained in control groups before and after the induction of the oedema on both the ipsilateral (injected) and contralateral (noninjected) limbs. All arthritic control rats showed 


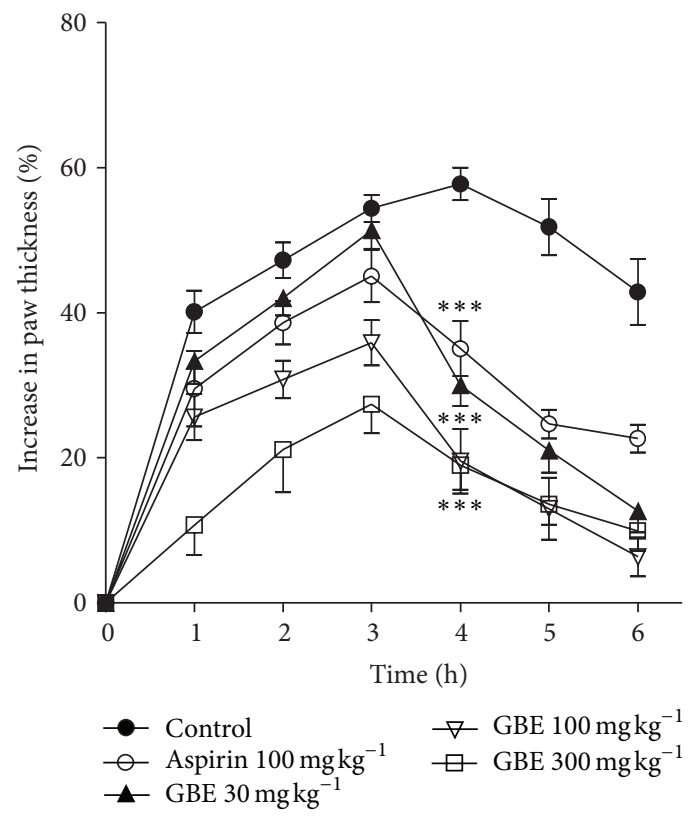

(a)

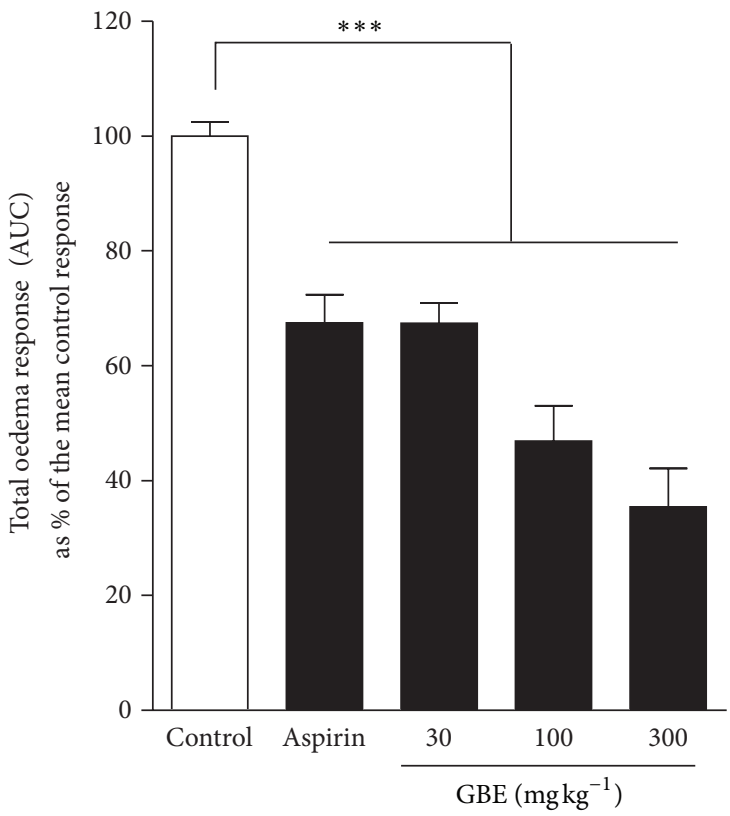

(b)

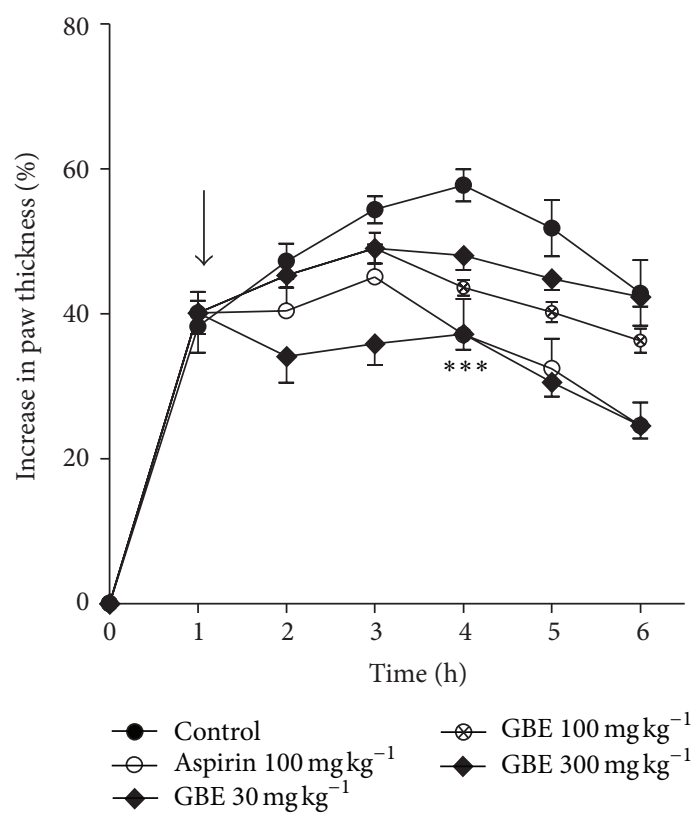

(c)

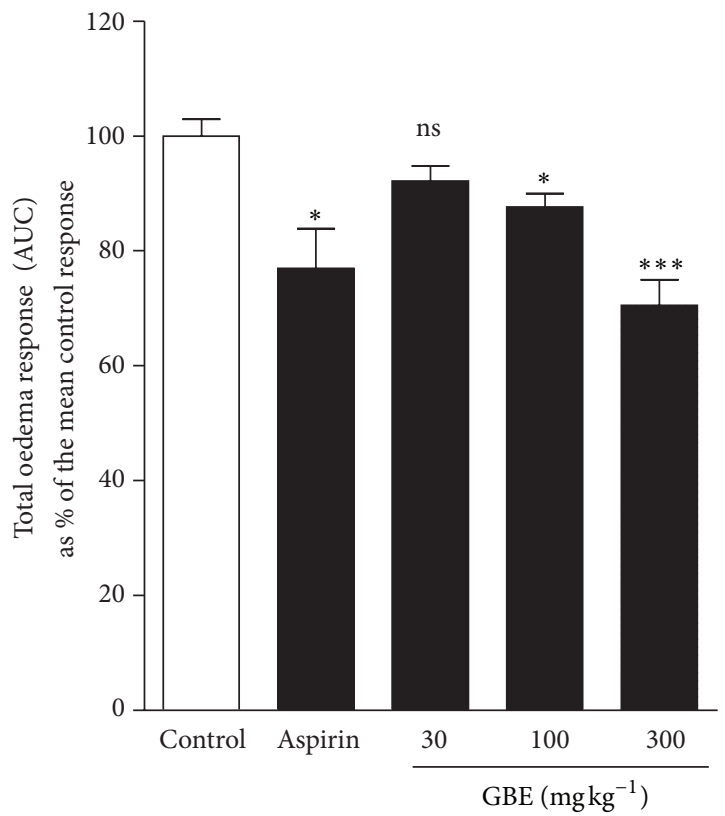

(d)

FIGURE 1: Effect of G. brevis extract (GBE) on carrageenan-induced oedema in mice. ICR mice (25-30 g) were injected with $50 \mu \mathrm{L}$ of a $1 \%$ carrageenan suspension into the subplantar tissue of the right hind paw. Oedema was monitored at $1 \mathrm{~h}$ intervals over $6 \mathrm{~h}$ as percentage increase in paw thickness (a and c), and total oedema induced during the $6 \mathrm{~h}$ was calculated as area under the time course curves, AUC (b and d). Drug effects were evaluated by comparing the maximal and total oedema responses attained during $6 \mathrm{~h}$ in drug-treated groups with the corresponding values attained in drug vehicle-treated inflamed control groups. In the preventive (prophylactic) protocol (left panel), drugvehicle, GBE 30,100, and $300 \mathrm{mg} \mathrm{kg}^{-1}$, and aspirin $100 \mathrm{mg} \mathrm{kg}^{-1}$ were given orally $1 \mathrm{~h}$ before the induction of the oedema while, in the curative (therapeutic) protocol (right panel), treatment was done $1 \mathrm{~h}$ after oedema induction. Data is presented as mean \pm s.e.m. $(n=5) .{ }^{* * *} P \leq 0.0001$, ${ }^{* *} P \leq 0.01$, and ${ }^{* *} P \leq 0.05$ when compared with control. Arrow indicates point of extract administration in the therapeutic protocol. 


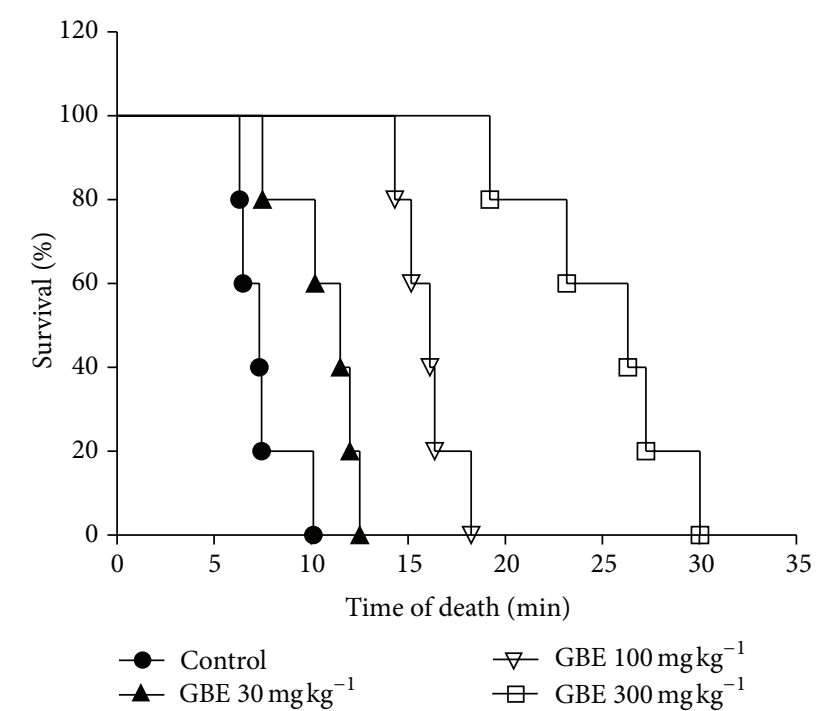

FIgURE 2: Effect of G. brevis extract (GBE) on compound 48/80induced anaphylaxis in mice. C57BL/6 mice (25-30 g) were pretreated for $1 \mathrm{~h}$ with saline, GBE 30,100 , and $300 \mathrm{mg} \mathrm{kg}^{-1}(n=5)$. Compound $48 / 80$ was injected $\left(10 \mathrm{mg} \mathrm{kg}^{-1}\right.$, i.p.) and mortality monitored for $1 \mathrm{~h}$ after induction of anaphylactic shock. The experimental results were analysed using the Log-rank (Mantel Cox) test and the survival rates were significant ${ }^{* * *} P \leq 0.0002$ compared to the salinetreated control mice.

acute inflammatory oedema at the ipsilateral paw (Figures 5(a) and 5(e)) followed by subsequent chronic polyarthritic phase in which the inflammation had spread to the contralateral limb (Figure 5(c)). There was no significant change throughout the study in the paw volume of the noninflamed control groups that were injected with IFA (Figure 5(a)).

Daily prophylactic administration over 28 days of diclofenac $6 \mathrm{mg} \mathrm{kg}^{-1}$ and GBE at 30, 100, and $300 \mathrm{mg} \mathrm{kg}^{-1}$ produced a significant $(P \leq 0.001)$ reduction of the maximal adjuvant-induced swelling to $72.80 \pm 8.96 \%, 125.08 \pm 8.49 \%$, $101.25 \pm 7.43 \%$, and $47.75 \pm 7.12 \%$, respectively, compared to the mean maximal control swelling of $150.58 \pm 9.34 \%$ (Figure 5(a)). The total adjuvant-induced response (AUC) over 28 days (polyarthritis) was dose dependently significantly $(P \leq 0.0001)$ reduced to $63.14 \pm 4.09 \%, 76.77 \pm$ $2.93 \%, 75.05 \pm 2.41 \%$, and $42.07 \pm 1.92 \%$ (Figure $5(\mathrm{~b})$ ), respectively, of the mean inflamed group response corresponding, respectively, to $36.86 \pm 5.77 \%, 23.23 \pm 5.02 \%, 24.95 \pm$ $4.73 \%$, and $57.93 \pm 4.50 \%$ inhibitions of the total oedema response in the ipsilateral limb. On the acute phase of the arthritic response (day $0-10$ ), the mean maximal oedema response was significantly $(P \leq 0.05)$ reduced to $50.34 \pm$ $4.61 \%, 51.80 \pm 1.75 \%, 51.08 \pm 1.40 \%$, and $44.87 \pm 7.41 \%$, respectively, compared to the mean maximal control response of $66.95 \pm 5.42 \%$ (Figure 5(a)) while the total adjuvantinduced response (AUC) over 10 days was significantly $(P \leq$ 0.002 ) reduced to $62.19 \pm 6.62 \%, 59.08 \pm 1.06 \%, 59.99 \pm 0.97 \%$, and $61.59 \pm 5.2 \%$ (Figure 5(b)) presenting $37.81 \pm 9.67 \%$, $40.92 \pm 7.12 \%, 40.01 \pm 7.11 \%$, and $38.41 \pm 8.78 \%$ inhibitions of the total oedema response, respectively.
On the contralateral hind limb, diclofenac and GBE administered prophylactically significantly $(P \leq 0.0001)$ suppressed the mean maximal oedema swelling in 28 days to $13.85 \pm 3.61 \%, 30.76 \pm 3.66 \%, 22.87 \pm 4.15 \%$, and $17.12 \pm$ $4.35 \%$ relative to the mean maximal control swelling of $92.20 \pm 8.95 \%$ (Figure 5(c)) while the total oedema response was in a dose-dependent manner significantly $(P \leq 0.001)$ reduced to $32.00 \pm 2.29 \%, 50.14 \pm 6.98 \%, 35.73 \pm 2.76 \%$, and $33.62 \pm 3.94 \%$, respectively, of the mean control response (Figure 5(d)) corresponding to $68.00 \pm 5.62 \%, 49.86 \pm 8.66 \%$, $64.27 \pm 5.83 \%$, and $66.38 \pm 6.47 \%$ inhibitions of the total oedema response, respectively.

In a separate experiment where drug administration commenced 10 days after the induction of the arthritis (curative), daily administration of diclofenac $6 \mathrm{mg} \mathrm{kg}^{-1}$ and the Glyphaea brevis extract 30,100 , and $300 \mathrm{mg} \mathrm{kg}^{-1}$ on the ipsilateral limb caused a significant $(P \leq 0.001)$ suppression of the mean maximal adjuvant-induced swelling on the 28th day, respectively, to $63.10 \pm 5.91 \%, 109.60 \pm 5.03 \%, 88.41 \pm$ $3.79 \%$, and $67.42 \pm 7.91 \%$ of the mean maximal control swelling of $150.58 \pm 9.34 \%$ (Figure $5(\mathrm{e})$ ). The total adjuvantinduced swelling (AUC) during the experimental period was also dose dependently significantly $(P \leq 0.05)$ suppressed, respectively, to $78.83 \pm 3.92 \%, 88.03 \pm 2.32 \%, 78.31 \pm 5.09 \%$, and $75.89 \pm 1.50 \%$ (Figure 5(f)) presenting $26.17 \pm 5.66 \%, 11.97 \pm$ $4.69 \%, 21.69 \pm 6.52 \%$, and $24.11 \pm 4.34 \%$ inhibitions of the total oedema response, respectively. On the contralateral limbs GBE effects were similar as described (results not shown).

\section{Discussion}

In this report, we show that oral treatment of rodents with $70 \%$ aqueous ethanol extract of Glyphaea brevis exerts inhibitory effects on carrageenan-induced oedema, a model of acute inflammation, systemic anaphylaxis, and adjuvantinduced arthritis, a model of chronic inflammation.

Carrageenan-induced mouse paw oedema has a wide application in the test of new anti-inflammatory drugs as well as in the study of mechanisms involved in inflammation [36] and is reported to exhibit a biphasic response with the first phase mediated by histamine and serotonin while the second phase is by prostaglandins with nitric oxide with kinins maintaining the oedema between the two phases [37]. A dose-dependent suppression of the oedema was displayed by the extract when it was given prophylactically. Our findings in the mouse agrees with an earlier report on the inhibitory effect of the aqueous ethanol extract of the stem bark of Glyphaea brevis on acute inflammation in the carrageenan-induced oedema model in 7-day-old cockerels [22]. The extract administered after the onset of the inflammatory reaction could also suppress significantly both the maximal oedema response and the total oedema response. The ability of the extract to exert anti-inflammatory effects both prophylactically and therapeutically suggests that it possibly acts by inhibiting the release, synthesis, and/or action of mediators involved in acute inflammation. The exact mechanism, however, needs to be established. 


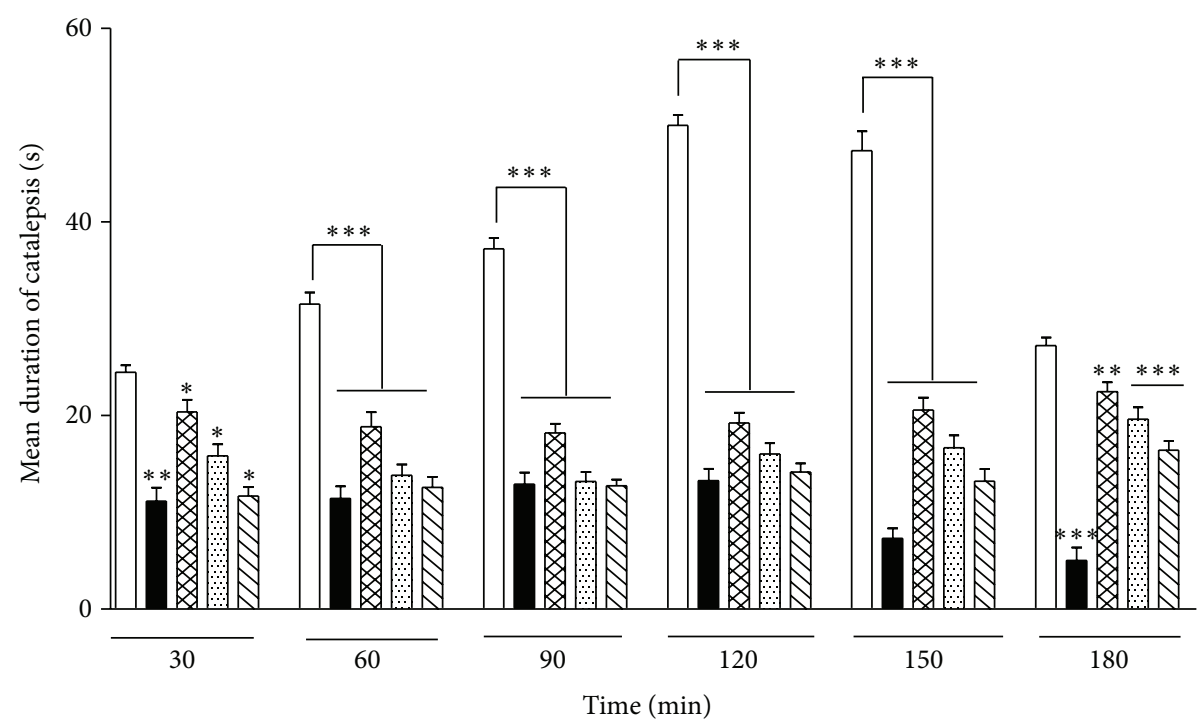

(a)

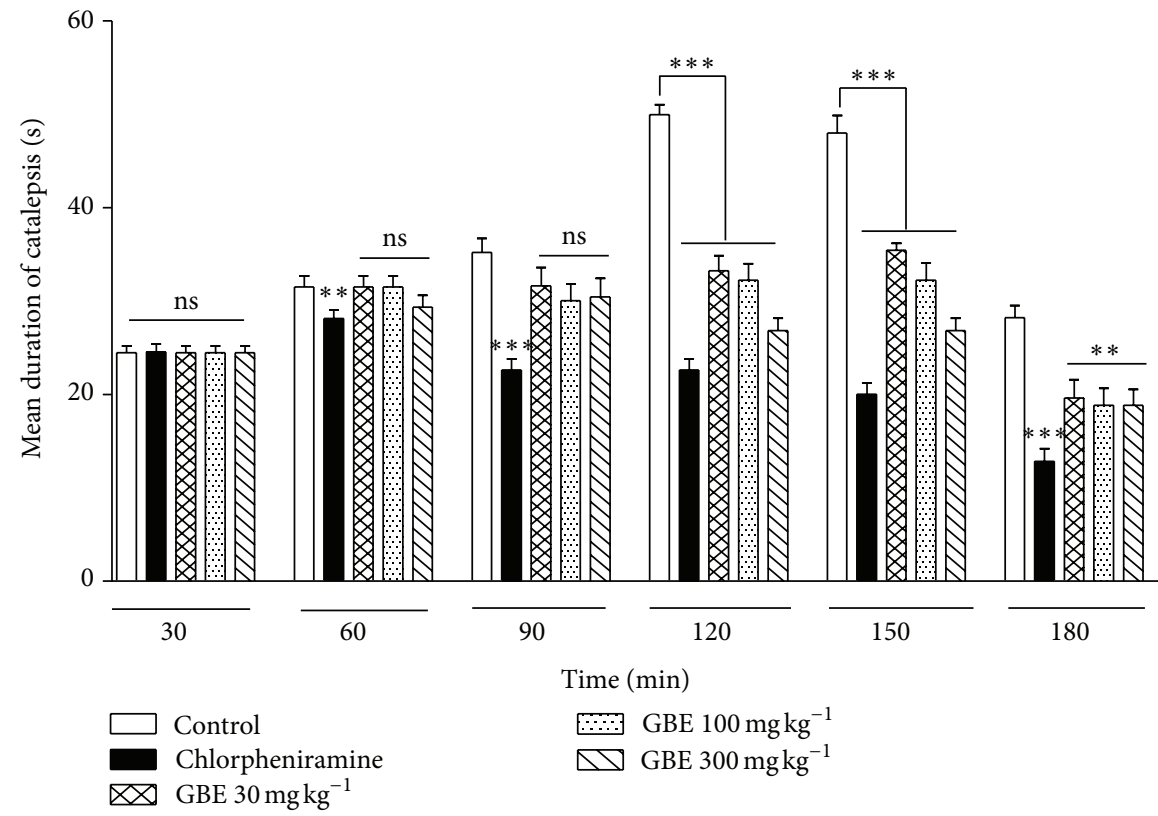

(b)

FIGURE 3: Effect of G. brevis extract (GBE) on clonidine-induced catalepsy. 8-10-week-old ICR mice (20-30 g) received clonidine $1 \mathrm{mg} \cdot \mathrm{kg}^{-1}$, s.c. and their forepaws placed on a horizontal bar $(1 \mathrm{~cm}$ in diameter, $10 \mathrm{~cm}$ above the table). The duration of catalepsy was measured at $30 \mathrm{~min}$ intervals up to $180 \mathrm{~min}$ after administration of clonidine. (a) In the preventive (prophylactic) protocol, vehicle $\left(5 \mathrm{~mL} \mathrm{~kg}{ }^{-1}\right), \mathrm{GBE}(30,100$, and $300 \mathrm{mg} \mathrm{kg}^{-1}$ ), and chlorpheniramine $\left(10 \mathrm{mg} \mathrm{kg}^{-1}\right.$ ) were given orally for 2 consecutive days ending 30 min before clonidine injection. (b) In the curative (therapeutic) protocol drug treatment commenced $1 \mathrm{~h}$ after induction of catalepsy. Values are mean \pm s.e.m. $(n=5)$. Data was subjected to two-way (treatment $\times$ time) repetitive measures analysis of variance (ANOVA) with Bonferroni's post hoc test. Significance between groups of vehicle and drug/extract-treated mice ${ }^{* * *} P \leq 0.0001,{ }^{* *} P \leq 0.01,{ }^{*} P \leq 0.05$, ns is nonsignificant.

Anaphylactic shock is an extreme and fatal allergic reaction, and in mice it is reportedly mediated by two pathways: an IgE-dependent pathway with IgE-mast cells as the major player [38] and another pathway mediated by IgG1 with macrophages and basophils as the major players [39]. The early clinical and experimental evidence suggests that systemic anaphylaxis mediated by mast cell degranulation results in the rapid release of preformed mediators, including histamine, proteoglycans, serotonin, lipid-derived mediators, and cytokines $[12,40]$. These mediators reportedly act on target cells to present with cardiovascular effects of vasodilation, increased vascular permeability, hypotension, bronchospasm and, as a result, shock [41]. The main organs involved in the early stages of anaphylaxis are the skin (urticaria and angioedema) and the respiratory tract (laryngeal oedema and bronchospasm). However, dysfunction of the central 

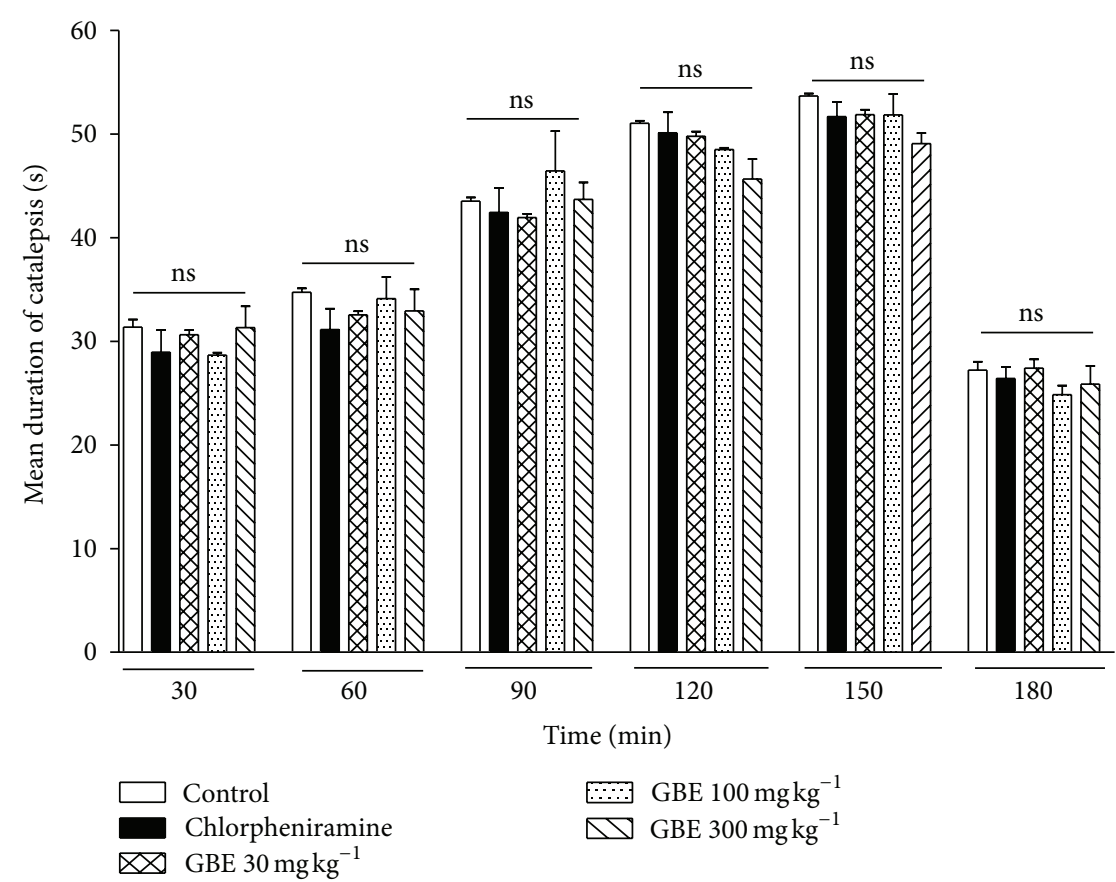

FIGURE 4: Effect of G. brevis extract (GBE) on haloperidol-induced catalepsy. 8-10-week-old ICR mice (20-30 g) received haloperidol $1 \mathrm{mg} \cdot \mathrm{kg}^{-1}$, s.c. and their forepaws placed on a horizontal bar $(1 \mathrm{~cm}$ in diameter, $10 \mathrm{~cm}$ above the table). The duration of catalepsy was measured at $30 \mathrm{~min}$ intervals up to $180 \mathrm{~min}$ after administration of haloperidol. Drug-vehicle $\left(5 \mathrm{~mL} \mathrm{~kg}^{-1}\right), \mathrm{GBE}\left(30,100\right.$, and $\left.300 \mathrm{mg} \mathrm{kg}{ }^{-1}\right)$, and chlorpheniramine $\left(10 \mathrm{mg} \mathrm{kg}^{-1}\right)$ were given orally for 2 consecutive days ending $30 \mathrm{~min}$ before haloperidol injection. Values are mean \pm s.e.m. $(n=5)$. Data was subjected to two-way (treatment $\times$ time) repetitive measures analysis of variance (ANOVA) with Bonferroni's post hoc test. Differences were considered significant at $P \leq 0.05$, ns is nonsignificant.

and peripheral cardiovascular systems usually dictates the outcome of anaphylactic events [42]. A drug capable of suppressing or preventing these effects must exhibit a potent antiallergic action. Experimentally, compound 48/80 stimulates mast cells and initiates the activation of signal transduction pathways, through the activation of $\mathrm{G}$ proteins $[43,44]$ leading to the release of the proinflammatory mediators such as histamine, heparin, lipid-derived mediators, and various cytokines [12]. Eventually, a perturbation in the membrane [45] occurs as these mediators cause an increase in the permeability of the lipid bilayer membrane. Our findings showing that prior treatment of the mice with GBE was able to exert a delay in the time of mortality of the animals that were injected with the compound 48/80 suggest that GBE possibly stabilizes the lipid bilayer membrane. This in turn significantly suppressed the perturbation from being induced by compound $48 / 80$ and therefore regulated the in vivo degranulation of the mast cells in the mice through stabilizing the membrane fluidity. In addition to inhibiting the degranulation of mast cells, GBE exhibits anti-inflammatory activity which might act in synergy with its antiallergic effect in the treatment of allergic inflammation.

Catalepsy, a condition in which an animal maintains an imposed posture for a long time before regaining normal posture, is a sign of extrapyramidal effect of drugs that increase histamine release in the brain or inhibit dopaminergic transmission. Histamine is frequently used as an indicator of mediators in IgE-dependent immediatetype anaphylaxis. While Schwartz reports that histamine containing mast cells have been identified in the brain [46], Chopra and Dandiya also demonstrate that different stages of catalepsy directly correlate with the histamine content of the brain [47]. It is also established that while clonidine releases histamine from mast cells in a similar manner to a selective degranulator compound 48/80 [48], it causes degranulation without causing any damage to the cell wall [49]. Jadhav et al. observed that clonidine-induced catalepsy in the mouse is mediated by histamine release from the mast cells acting via $\mathrm{H}_{1}$ receptors [50] and consequently inhibited by histamine $\mathrm{H}_{1}$ receptor antagonists but not by $\mathrm{H}_{2}$ receptor antagonists [51]. In this study, our results revealed a dosedependent suppression of clonidine-induced catalepsy by both $\mathrm{GBE}$ and the $\mathrm{H}_{1}$-receptor antagonist, chlorpheniramine, when administered either prophylactically or therapeutically and is strongly indicative of an indirect antihistaminic $\mathrm{H}_{1}$ receptor activity of the extract. Haloperidol, a nonselective D2 dopamine antagonist, also induces catalepsy by primarily blocking the dopamine receptors in the striatum and agents that increase dopaminergic transmission inhibit haloperidol-induced catalepsy [52]. In our study, both the antihistaminic drug chlorpheniramine and GBE failed to inhibit haloperidol-induced catalepsy consistent with the findings that haloperidol-induced catalepsy is independent of histamine release. Again failure of the extract to inhibit haloperidol-induced catalepsy also demonstrates that GBE may not have any effect on dopaminergic transmission. Taken together with the effect of the extract on compound 48/80induced anaphylaxis, GBE possibly possesses antihistaminic 


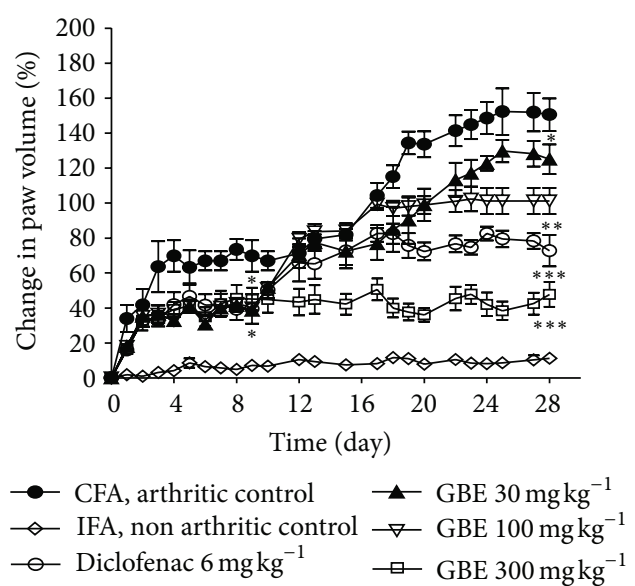

(a)
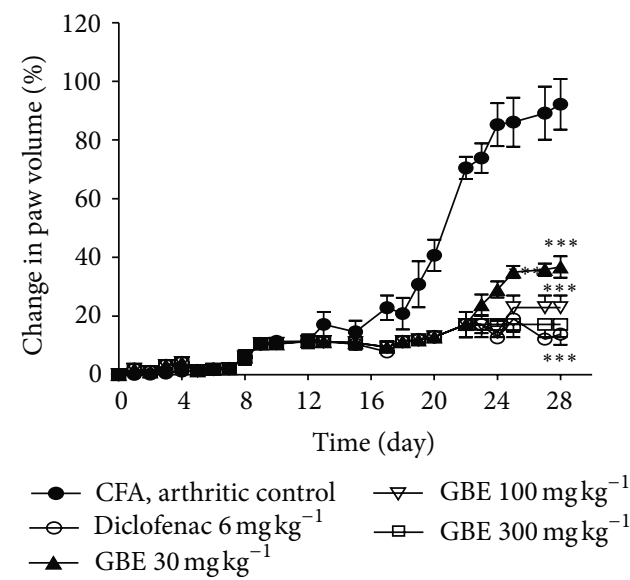

(c)

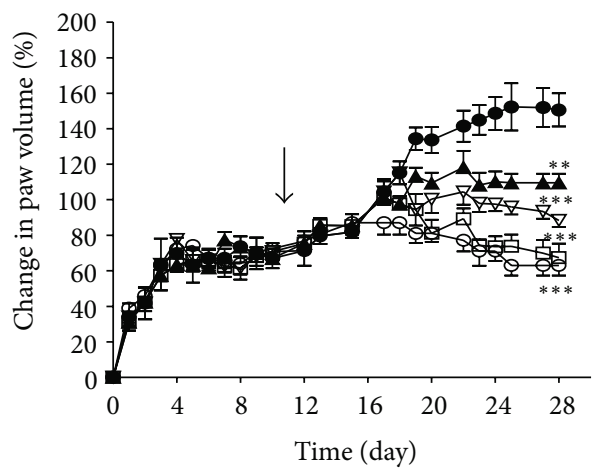

$\begin{array}{ll}- \text { - CFA, arthritic control } & \rightarrow \text { GBE } 100 \mathrm{mg} \mathrm{kg}^{-1} \\ - \text { Diclofenac } 6 \mathrm{mg} \mathrm{kg}^{-1} & \square \text { GBE } 300 \mathrm{mg} \mathrm{kg}^{-1} \\ - \text { GBE } 30 \mathrm{mg} \mathrm{kg}^{-1} & \end{array}$

(e)

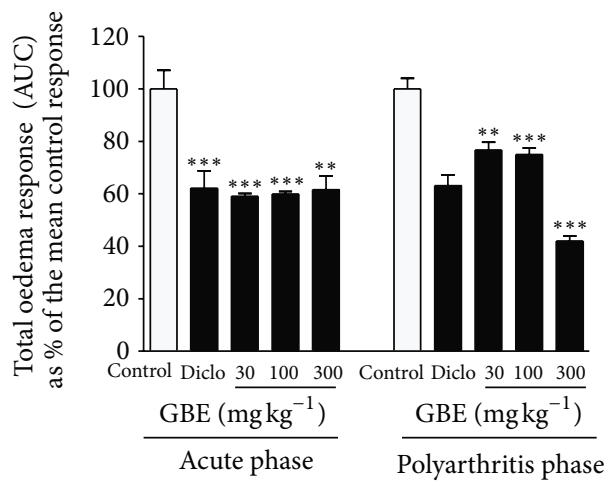

(b)

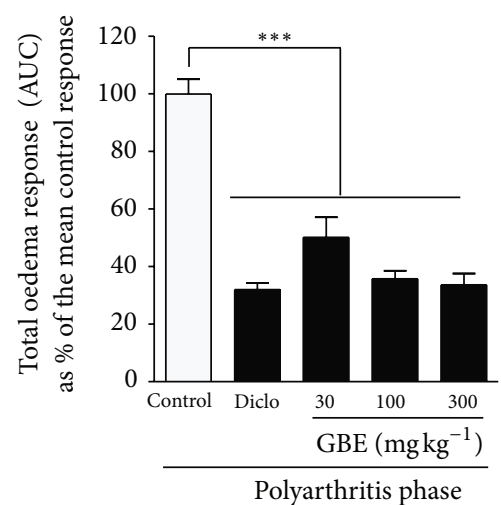

(d)

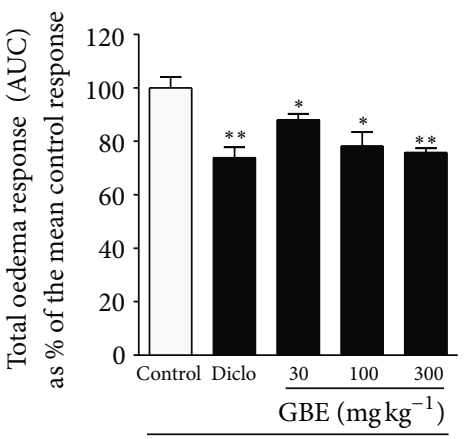

Polyarthritis phase

(f)

Figure 5: Effect of G. brevis extract (GBE) on adjuvant-induced arthritis. Sprague-Dawley rats (200-250 g) were injected intraplantar with $100 \mu \mathrm{L}$ of CFA or IFA into the right hind paw. Foot volume was measured by water displacement plethysmography daily for 28 days. The oedema component of inflammation was monitored as the percentage change in paw volume (a, c, and e) and the total oedema induced during the acute and polyarthritis phases calculated as area under the time course curves, AUC ( $b$, d, and $\mathrm{f}$ ). In the preventive protocol (top and middle panels), drug vehicle, diclofenac $6 \mathrm{mg} \mathrm{kg}^{-1}$, or GBE 30,100, and $300 \mathrm{mg} \mathrm{kg}^{-1}$ were given orally $1 \mathrm{~h}$ before the induction of the arthritis and daily for 28 days while, in the curative protocol (bottom panel), treatment commenced 10 days after arthritis induction. Drug effects were evaluated by comparing the maximal and total oedema responses attained during 28 days in drug-treated groups with the corresponding values attained in drug-vehicle-treated inflamed control groups. Data is presented as mean \pm s.e.m. $(n=5){ }^{* * *} P \leq 0.0001$, ${ }^{* *} P \leq 0.01,{ }^{* *} P \leq 0.05$ when compared with vehicle-treated control group. Arrow indicates point of extract administration in the therapeutic protocol. 
activity and mast cell stabilizing ability in a dose-dependent manner and consistent with earlier findings that extracts with antihistaminic or mast cell stabilizing effect inhibit clonidineinduced catalepsy [51] and as reported for Allium sativum and Terminalia belerica, Clerodendrum serratum, and Ficus benghalensis [53-55].

As events in carrageenan-induced oedema are very similar to those occurring during the primary phase of adjuvantinduced arthritis and these correspond to those in the early exudative phase of inflammation [56, 57], we investigated the effect of GBE on Freund's rat adjuvant-induced arthritis. Pearson and Wood report that rat adjuvant arthritis (AA) is a chronic, polyarticular, erosive type of arthritis induced by an injection of heat-killed mycobacteria [58]. AA is widely used for studying the pathogenesis of rheumatoid arthritis, RA, and for searching new drugs for treatment of rheumatoid disease [59-61]. In the present study, rats were selected to induce arthritis because rats develop a chronic swelling in multiple joints with influence of inflammatory cells, erosion of joint cartilage, and bone destruction. These inflammatory changes ultimately result in the complete destruction of joint integrity and functions in the affected rats [62] through the release of number of mediators like cytokines such as interleukin-1B, (IL-IB), tumor necrosis factor alpha (TNF$\alpha$ ), Granulocyte macrophage colony-stimulating factor (GMCSF), interferon's, and prostaglandins such as (PGDF) [61, 63]. Turull and Queralt showed that in the pathogenesis of adjuvant arthritis in the rat autoantigens that cross-react with Mycobacteria are implicated and that adjuvant arthritis appears as a consequence of an immune response to cell wall of Mycobacterium. Compared with normal rats, AA rats had higher levels of IgG anti-Mycobacterium antibodies and the delayed skin reactions induced by the soluble fraction of Mycobacterium [64]. GBE at doses used significantly decreased humoral immune responses. At the same time, treatment with GBE at all three doses assayed inhibited the delayed-type hypersensitivity seen in arthritic animals. This work suggests that GBE might exert its effect through its influence on the cellular and on the humoral immune response to the Mycobacterium in adjuvant-induced arthritic rats. Hoffmann et al. indicate that prognosis of rat adjuvantinduced arthritis can be divided into three phases as in human rheumatoid arthritis. These phases start with the induction phase which has no evidence of synovitis, followed by early synovitis, and finally late synovitis with progressive joint destruction [65]. A good antirheumatic agent should be able to block one or more of these phases. The aqueous ethanol extract, GBE, used in the work suppressed joint inflammation and synovitis. GBE suppressed the swelling associated with both the acute and polyarthritic phases of adjuvant-induced arthritis when used both prophylactically and therapeutically. This is significant because Kaibara et al. could demonstrate that cyclosporine, an immunosuppressive drug, prevented the onset of collagen-induced arthritis in rats; however, when used after the disease had been established, it exacerbated the condition [66]. Again as shown by Larsson et al. limonide, an experimental drug developed against heterologous collagen-induced arthritis, exhibited similar paradoxical effects [67]. These earlier findings strongly suggest that demonstrated anti-inflammatory effect of a drug given prior to the induction of inflammation does not necessarily guarantee the same effect when given after the induction of the inflammation. Therefore on both the carrageenan-induced paw oedema and rat adjuvant-induced arthritis models, the ability of GBE to exert anti-inflammatory effects both prophylactically and therapeutically support the presence of compounds most likely exerting inhibitory effects through interference with the pathophysiological processes underlying inflammation. The exact mechanism, however, needs to be established. In addition to reducing the general swelling, the extract prevented the systemic spread of the arthritis to the noninjected limb suggesting an effective anti-inflammatory action.

Interestingly, phytochemical screening of the plant revealed the presence of several therapeutically valued constituents including flavonoids, tannins $[26,28]$, and steroids [30]. Therefore several mechanisms could be responsible for the actions of the extract. For example, flavonoids have powerful antioxidant actions $[68,69]$ and exhibit significant analgesic activity primarily by targeting and inhibiting prostaglandins, PGs [70, 71], through inhibition of eicosanoid biosynthesis. PGs are the end products of the cyclooxygenase and lipoxygenase pathways [72] and are implicated in various immunological responses. Again flavonoids suppress the intracellular $\mathrm{Ca}^{2+}$ ion elevation and consequently depress the release of proinflammatory mediators such as TNF $\alpha$ [73]. In this regard, flavonoids such as quercetin have potent effects on acute inflammation [74]. Tannins are also known to be potent inhibitors of cyclooxygenase-1 (COX-1) and with antiphlogistic activity [75]. The mechanisms of anti-inflammatory activity may be in part accounted for by the antiphlogistic action of the tannins. Steroids (glucocorticoids) as anti-inflammatory agents act by different mechanisms via the steroid receptor to regulate gene transcription either positively (transactivation) or negatively (transrepression) [76, 77]. Again, cross-talk between the steroid and the signalling pathways which are triggered on mast cell activation serves as another mode of their action since some upstream molecules are important in the phosphorylation of transcription factors [78]. In sum, the anti-inflammatory actions of the total crude extract are attributed to effects of the individual constituents. The established anti-inflammatory properties of G. brevis, warrant further evaluation of its clinical utility in mast cell-mediated immediate and delayed allergic diseases.

\section{Conclusion}

The extract of Glyphaea brevis inhibits in vivo degranulation of mast cells and thereby suppresses allergy through inhibition of histamine release from mast cells. Additionally, Glyphaea brevis exhibits anti-inflammatory activity and attenuates Freund's adjuvant-induced arthritis.

\section{Conflict of Interests}

The authors declare no conflict of interests. 


\section{Acknowledgment}

The authors place on record their profound gratitude to the Chief Technician: Mr. Thomas Ansah of the Pharmacology Department for the technical support he offered during this study.

\section{References}

[1] F. E. R. Simons, A. J. Frew, I. J. Ansotegui et al., "Risk assessment in anaphylaxis: current and future approaches," Journal of Allergy and Clinical Immunology, vol. 120, no. 1, supplement, pp. S2-S24, 2007.

[2] S. H. Sicherer and D. Y. M. Leung, "Advances in allergic skin disease, anaphylaxis, and hypersensitivity reactions to foods, drugs, and insects," Journal of Allergy and Clinical Immunology, vol. 116, no. 1, pp. 153-163, 2005.

[3] P. A. Greenberger, "Drug allergy," Journal of Allergy and Clinical Immunology, vol. 117, no. 2, supplement, pp. S464-S470, 2006.

[4] S. A. Bock, A. Muoz-Furlong, and H. A. Sampson, "Fatalities due to anaphylactic reactions to foods," Journal of Allergy and Clinical Immunology, vol. 107, no. 1, pp. 191-193, 2001.

[5] J. Wang and H. A. Sampson, "Food anaphylaxis," Clinical and Experimental Allergy, vol. 37, no. 5, pp. 651-660, 2007.

[6] P. A. Nigrovic and D. M. Lee, "Mast cells in inflammatory arthritis," Arthritis Research and Therapy, vol. 7, no. 1, pp. 1-11, 2005.

[7] J.-P. Kinet, "The high-affinity IgE receptor (FceRI): from physiology to pathology," Annual Review of Immunology, vol. 17, no. 1, pp. 931-972, 1999.

[8] C. Benoist and D. Mathis, "Mast cells in autoimmune disease," Nature, vol. 420, no. 6917, pp. 875-878, 2002.

[9] D. Lagunoff, T. W. Martin, and G. Read, "Agents that release histamine from mast cells," Annual Review of Pharmacology and Toxicology, vol. 23, pp. 331-351, 1983.

[10] S. Kraft and J. P. Kinet, "New developments in FceRI regulation, function and inhibition," Nature Review Immunology, vol. 7, no. 5, pp. 365-378, 2007.

[11] M. A. Beaven, "Our perception of the mast cell from Paul Ehrlich to now," European Journal of Immunology, vol. 39, no. 1, pp. 11-25, 2009.

[12] S. F. Kemp and R. F. Lockey, "Anaphylaxis: a review of causes and mechanisms," Journal of Allergy and Clinical Immunology, vol. 110, no. 3, pp. 341-348, 2002.

[13] A. Omoto, Y. Kawahito, I. Prudovsky et al., "Copper chelation with tetrathiomolybdate suppresses adjuvant-induced arthritis and inflammation-associated cachexia in rats," Arthritis Research \& Therapy, vol. 7, no. 6, pp. R1174-R1182, 2005.

[14] M. C. V. Rizzo and D. Solé, "Inhaled corticosteroids in the treatment of respiratory allergy: safety vs. efficacy," Jornal de Pediatria, vol. 82, no. 5, supplement, pp. S198-S205, 2006.

[15] P. S. Loewen, "Review of the selective COX-2 inhibitors celecoxib and rofecoxib: focus on clinical aspects," Canadian Journal of Emergency Medicine, vol. 4, no. 4, pp. 268-275, 2002.

[16] A. Mirshafiey, S. Cuzzocrea, B. H. A. Rehm, and H. Matsuo, "M2000: a revolution in pharmacology," Medical Science Monitor, vol. 11, no. 8, pp. PI53-PI63, 2005.

[17] K. J. L. Choo, F. E. R. Simons, and A. Sheikh, "Glucocorticoids for the treatment of anaphylaxis," Cochrane Database of Systematic Reviews, vol. 4, Article ID CD007596, 2012.
[18] D. D. Obiri, N. Flink, J. V. Maier et al., "PEST-domain-enriched tyrosine phosphatase and glucocorticoids as regulators of anaphylaxis in mice," Allergy, vol. 67, no. 2, pp. 175-182, 2012.

[19] N. Ivanovska and S. Philipov, "Immunosuppressive activity of isoquinoline alkaloids," Pharmaceutical and Pharmacological Letters, vol. 6, no. 2, pp. 79-81, 1996.

[20] P. E. Lipsky and X.-L. Tao, "A potential new treatment for rheumatoid arthritis: thunder god vine," Seminars in Arthritis and Rheumatism, vol. 26, no. 5, pp. 713-723, 1997.

[21] K. Riehemann, B. Behnke, and K. Schulze-Osthoff, "Plant extracts from stinging nettle (Urtica dioica), an antirheumatic remedy, inhibit the proinflammatory transcription factor NFкB," FEBS Letters, vol. 442, no. 1, pp. 89-94, 1999.

[22] R. A. Dickson, E. Ekuadzi, K. Annan, and G. Komlaga, "Antibacterial, anti-inflammatory, and antioxidant effects of the leaves and stem bark of Glyphaea brevis (Spreng) Monachino (Tiliaceae): a comparative study," Pharmacognosy Research, vol. 3, no. 3, pp. 166-172, 2011.

[23] N. R. Mshana, D. K. Abbiw, I. Addae-Mensah et al., "Traditional medicine and pharmacopoeia: contribution to the revision of ethnobotanical and floristic studies in Ghana," Tech. Rep. 579, OAU/STRC, 2000.

[24] D. Abbiw, Useful Plants of Ghana, Intermediate Technical Publications and Royal Botanic Gardens, Kew, UK, 1990.

[25] E. Noumi and A. Yomi, "Medicinal plants used for intestinal diseases in Mbalmayo Region, Central Province, Cameroon," Fitoterapia, vol. 72, no. 3, pp. 246-254, 2001.

[26] S. Ogbonnia, J. van Staden, A. K. Jager, and H. A. Coker, "Anticonvulsant effects of Glyphaea brevis (Speng) Moraches leaf extracts in mice and preliminary phytochemical tests," Nigerian Quarterly Journal of Hospital Medicine, vol. 13, no. 3-4, pp. 62-64, 2003.

[27] E. J. T. Mbosso, S. Ngouela, J. C. A. Nguedia, V. P. Beng, M. Rohmer, and E. Tsamo, "In vitro antimicrobial activity of extracts and compounds of some selected medicinal plants from Cameroon," Journal of Ethnopharmacology, vol. 128, no. 2, pp. 476-481, 2010.

[28] W. Dakam, J. E. Oben, and J. Y. Ngogang, "Antioxidant activity and extractability of phenolic compounds from medicinal plants: a study of Glyphaea brevis spreng. (Monach.)," Pharmacologyonline, vol. 3, pp. 708-718, 2008.

[29] B. A. Ojelabi, J. O. Areola, and O. O. Babalola, "Roles of Glyphaea brevis (Spreng) extract in cadmium induced hepatocellular damage and oxidative stress in rabbit," E3 Journal of Biotechnology and Pharmaceutical Research, vol. 3, no. 7, pp. 123-128, 2012.

[30] E. J. K. Mbosso, R. Wintjens, B. N. Lenta, S. Ngouela, M. Rohmer, and E. Tsamo, "Chemical constituents from Glyphaea brevis and Monodora myristica: chemotaxonomic significance," Chemistry \& Biodiversity, vol. 10, no. 2, pp. 224-232, 2013.

[31] C. A. Winter, E. A. Risley, and G. W. Nuss, "Carrageenininduced edema in hind paw of the rat as an assay for antiiflammatory drugs," Proceedings of the Society for Experimental Biology and Medicine, vol. 111, pp. 544-547, 1962.

[32] S.-H. Kim, C.-H. Choi, S.-Y. Kim, J.-S. Eun, and T.-Y. Shin, "Anti-allergic effects of Artemisia iwayomogi on mast cellmediated allergy model," Experimental Biology and Medicine, vol. 230, no. 1, pp. 82-88, 2005.

[33] S. Ferre, T. Guix, G. Prat, F. Jane, and M. Casas, "Is experimental catalepsy properly measured?" Pharmacology Biochemistry and Behavior, vol. 35, no. 4, pp. 753-757, 1990. 
[34] C. M. Pearson, "Development of arthritis, periarthritis and periostitis in rats given adjuvants," Proceedings of the Society for Experimental Biology and Medicine, vol. 91, no. 1, pp. 95-101, 1956.

[35] M. Fereidoni, A. Ahmadiani, S. Semnanian, and M. Javan, "An accurate and simple method for measurement of paw edema," Journal of Pharmacological and Toxicological Methods, vol. 43, no. 1, pp. 11-14, 2000.

[36] I. Posadas, M. Bucci, F. Roviezzo et al., "Carrageenan-induced mouse paw oedema is biphasic, age-weight dependent and displays differential nitric oxide cyclooxygenase-2 expression," British Journal of Pharmacology, vol. 142, no. 2, pp. 331-338, 2004.

[37] P. Crunkhorn and S. C. Meacock, "Mediators of the inflammation induced in the rat paw by carrageenin," British Journal of Pharmacology, vol. 42, no. 3, pp. 392-402, 1971.

[38] F. D. Finkelman, "Anaphylaxis: lessons from mouse models," Journal of Allergy and Clinical Immunology, vol. 120, no. 3, pp. 506-515, 2007.

[39] I. Miyajima, D. Dombrowicz, T. R. Martin, J. V. Ravetch, J.P. Kinet, and S. J. Galli, "Systemic anaphylaxis in the mouse can be mediated largely through IgG1 and Fc $\gamma$ RIII: assessment of the cardiopulmonary changes, mast cell degranulation, and death associated with active or IgE- or IgG1-dependent passive anaphylaxis," Journal of Clinical Investigation, vol. 99, no. 5, pp. 901-914, 1997.

[40] J. Rivera and A. M. Gilfillan, "Molecular regulation of mast cell activation," Journal of Allergy and Clinical Immunology, vol. 117, no. 6, pp. 1214-1225, 2006.

[41] D. B. K. Golden, "What is anaphylaxis?" Current Opinion in Allergy and Clinical Immunology, vol. 7, no. 4, pp. 331-336, 2007.

[42] G. Marone, M. Bova, A. Detoraki, A. M. Onorati, F. W. Rossi, and G. Spadaro, "The human heart as a shock organ in anaphylaxis," Novartis Foundation Symposium, vol. 257, pp. 133149, 2004.

[43] M. Mousli, C. Bronner, J. Bockaert, B. Rouot, and Y. Landry, "Interaction of substance P, compound 48/80 and mastoparan with the $\alpha$-subunit $\mathrm{C}$-terminus of $\mathrm{G}$ protein," Immunology Letters, vol. 25, no. 4, pp. 355-358, 1990.

[44] A. Chahdi, P. F. Fraundorfer, and M. A. Beaven, "Compound 48/80 activates mast cell phospholipase D via heterotrimeric GTP-binding proteins," Journal of Pharmacology and Experimental Therapeutics, vol. 292, no. 1, pp. 122-130, 2000.

[45] K. Tasaka, M. Mio, and M. Okamoto, "Intracellular calcium release induced by histamine releasers and its inhibition by some antiallergic drugs," Annals of Allergy, Asthma and Immunology, vol. 56, no. 6, pp. 464-469, 1986.

[46] J. C. Schwartz, "Histaminergic mechanisms in brain," Annual Review of Pharmacology and Toxicology, vol. 17, pp. 325-339, 1977.

[47] Y. M. Chopra and P. C. Dandiya, "The relative role of brain acetylcholine and histamine in perphenazine catatonia and influence of antidepressants and diphenhydramine alone and in combination," Neuropharmacology, vol. 14, no. 8, pp. 555-560, 1975.

[48] A. D. Lakdawala, N. K. Dadkar, and A. N. Dohadwalla, "Action of clonidine on the mast cells of rats," Journal of Pharmacy and Pharmacology, vol. 32, no. 11, pp. 790-791, 1980.

[49] D. R. Stanworth, "Immediate hypersensitivity," in The Molecular Basis of the Allergic Response, A. Neuberger and E. L. Tatum, Eds., p. 73, North Holland Publishing Company, Amsterdam, The Netherlands, 1973.
[50] J. H. Jadhav, J. J. Balsara, and A. G. Chandorkar, "Involvement of histaminergic mechanisms in the cataleptogenic effect of clonidine in mice," Journal of Pharmacy and Pharmacology, vol. 35, no. 10, pp. 671-673, 1983.

[51] S. Dhanalakshmi, S. S. Khaserao, and S. B. Kasture, "Effect of ethanolic extract of some anti-asthmatic herbs on clonidine and haloperidol-induced catalepsy in mice," Oriental Pharmacy and Experimental Medicine, vol. 4, no. 2, pp. 95-99, 2004.

[52] P. R. Sanberg, "Haloperidol-induced catalepsy is mediated by postsynaptic dopamine receptors," Nature, vol. 284, no. 5755, pp. 472-473, 1980.

[53] B. A. Vyas and R. B. Vyas, "Effect of ethanolic extracts of Allium sativum and Terminalia belerica on clonidine-induced mast cell degranulation and clonidine and haloperidol-induced catalepsy in mice," International Journal of Pharmaceutical Research, vol. 1, no. 1, pp. 41-44, 2009.

[54] S. S. Bhujbal, D. Kumar, R. S. Deoda, S. M. Kewatkar, and M. J. Patil, "In vivo and in vitro antiasthmatic studies of Clerodendrum serratum linn," Pharmacologyonline, vol. 2, pp. 745-752, 2009.

[55] D. J. Taur, S. A. Nirmal, and R. Y. Patil, "Effect of various extracts of Ficus bengalensis bark on clonidine and haloperidol-induced catalepsy in mice," Pharmacologyonline, vol. 3, pp. 470-477, 2007.

[56] Y. Ozaki, "Antiinflammatory effect of Curcuma xanthorrhiza ROXB. and its active principles," Chemical and Pharmaceutical Bulletin, vol. 38, no. 4, pp. 1045-1048, 1990.

[57] G. N. Silva, F. R. Martins, M. E. Matheus, S. G. Leitão, and P. D. Fernandes, "Investigation of anti-inflammatory and antinociceptive activities of Lantana trifolia," Journal of Ethnopharmacology, vol. 100, no. 3, pp. 254-259, 2005.

[58] C. M. Pearson and F. D. Wood, "Studies of polyarthritis and other lesions induced in rats by injection of mycobacterial adjuvant. I. General clinical and pathologic characteristics and some modifying factors," Arthritis and Rheumatism, vol. 2, pp. 440-459, 1959.

[59] R. A. Greenwald, "Animal models for evaluation of arthritis drugs," Methods and Findings in Experimental and Clinical Pharmacology, vol. 13, no. 2, pp. 75-83, 1991.

[60] C. B. Schmidt-Weber, D. Pohlers, A. Siegling et al., "Cytokine gene activation in synovial membrane, regional lymph nodes, and spleen during the course of rat adjuvant arthritis," Cellular Immunology, vol. 195, no. 1, pp. 53-65, 1999.

[61] Y.-Q. Zheng and W. Wei, “Total glucosides of paeony suppresses adjuvant arthritis in rats and intervenes cytokinesignaling between different types of synoviocytes," International Immunopharmacology, vol. 5, no. 10, pp. 1560-1573, 2005.

[62] S. Sing and D. K. Majumdar, "Effect of fixed oil of Ocimum sanctum against experimentally induced arthritis and joint edema in laboratory animals," International Journal of Pharmacognosy, vol. 34, no. 3, pp. 218-222, 1996.

[63] S. E. Sweeney and G. S. Firestein, "Rheumatoid arthritis: regulation of synovial inflammation," International Journal of Biochemistry and Cell Biology, vol. 36, no. 3, pp. 372-378, 2004.

[64] À. Turull and J. Queralt, "Selective cyclooxygenase-2 (COX2) inhibitors reduce anti-Mycobacterium antibodies in adjuvant arthritic rats," Immunopharmacology, vol. 46, no. 1, pp. 71-77, 2000.

[65] J. C. Hoffmann, C. Herklotz, H. Zeidler, B. Bayer, H. Rosenthal, and J. Westermann, "Initiation and perpetuation of rat adjuvant arthritis is inhibited by the anti-CD2 monoclonal antibody 
(mAb) OX34," Annals of the Rheumatic Diseases, vol. 56, no. 12, pp. 716-722, 1997.

[66] N. Kaibara, T. Hotokebuchi, K. Takagishi, and I. Katsuki, "Paradoxical effects of cyclosporin A on collagen arthritis in rats," Journal of Experimental Medicine, vol. 158, no. 6, pp. 20073015, 1983.

[67] P. Larsson, S. Kleinau, R. Holmdahl, and L. Klareskog, "Homologous type II collagen-induced arthritis in rats. Characterization of the disease and demonstration of clinically distinct forms of arthritis in two strains of rats after immunization with the same collagen preparation," Arthritis and Rheumatism, vol. 33, no. 5, pp. 693-701, 1990.

[68] J. A. Vinson, Y. A. Dabbagh, M. M. Serry, and J. Jang, "Plant flavonoids, especially tea flavonols, are powerful antioxidants using an in vitro oxidation model for heart disease," Journal of Agricultural and Food Chemistry, vol. 43, no. 11, pp. 2800-2802, 1995.

[69] J. E. Brown and C. A. Rice-Evans, "Luteolin-rich artichoke extract protects low density lipoprotein from oxidation in vitro," Free Radical Research, vol. 29, no. 3, pp. 247-255, 1998.

[70] M. Ramesh, Y. N. Rao, A. V. N. Appa Rao et al., "Antinociceptive and anti-inflammatory activity of a flavonoid isolated from Caralluma attenuata," Journal of Ethnopharmacology, vol. 62, no. 1, pp. 63-66, 1998.

[71] K. R. Narayana, M. S. Reddy, M. R. Chaluvadi, and D. R. Krishna, "Bioflavonoids classification, pharmacological, biochemical effects and therapeutic potential," Indian Journal of Pharmacology, vol. 33, no. 1, pp. 2-16, 2001.

[72] C. Jothimanivannan, R. S. Kumar, and N. Subramanian, "Antiinflammatory and analgesic activities of ethanol extract of aerial parts of Justicia gendarussa Burm," International Journal of Pharmacology, vol. 6, no. 3, pp. 278-283, 2010.

[73] D. Kempuraj, B. Madhappan, S. Christodoulou et al., "Flavonols inhibit proinflammatory mediator release, intracellular calcium ion levels and protein kinase $\mathrm{C}$ theta phosphorylation in human mast cells," British Journal of Pharmacology, vol. 145, no. 7, pp. 934-944, 2005.

[74] M. Yerima, M. G. Magaji, A. H. Yaro, Y. Tanko, and M. M. Mohammed, "Analgesic and antiinflammatory activities of the methanolic leaves extract of Securinega virosa (Euphorbiaceae)," Nigerian Journal of Pharmaceutical Sciences, vol. 8, no. 1, pp. 47-53, 2009.

[75] H. Wagner, "Search for new plant constituents with potential antiphlogistic and antiallergic activity," Planta Medica, vol. 55, no. 3, pp. 235-241, 1989.

[76] I. M. Adcock, "Glucocorticoid-regulated transcription factors," Pulmonary Pharmacology and Therapeutics, vol. 14, no. 3, pp. 211-219, 2001.

[77] R. Hayashi, H. Wada, K. Ito, and I. M. Adcock, "Effects of glucocorticoids on gene transcription," European Journal of Pharmacology, vol. 500, no. 1-3, pp. 51-62, 2004.

[78] M. V. González, B. Jiménez, M. T. Berciano et al., "Glucocorticoids antagonize AP-1 by inhibiting the activation/phosphorylation of JNK without affecting its subcellular distribution," The Journal of Cell Biology, vol. 150, no. 5, pp. 1199-1207, 2000 . 

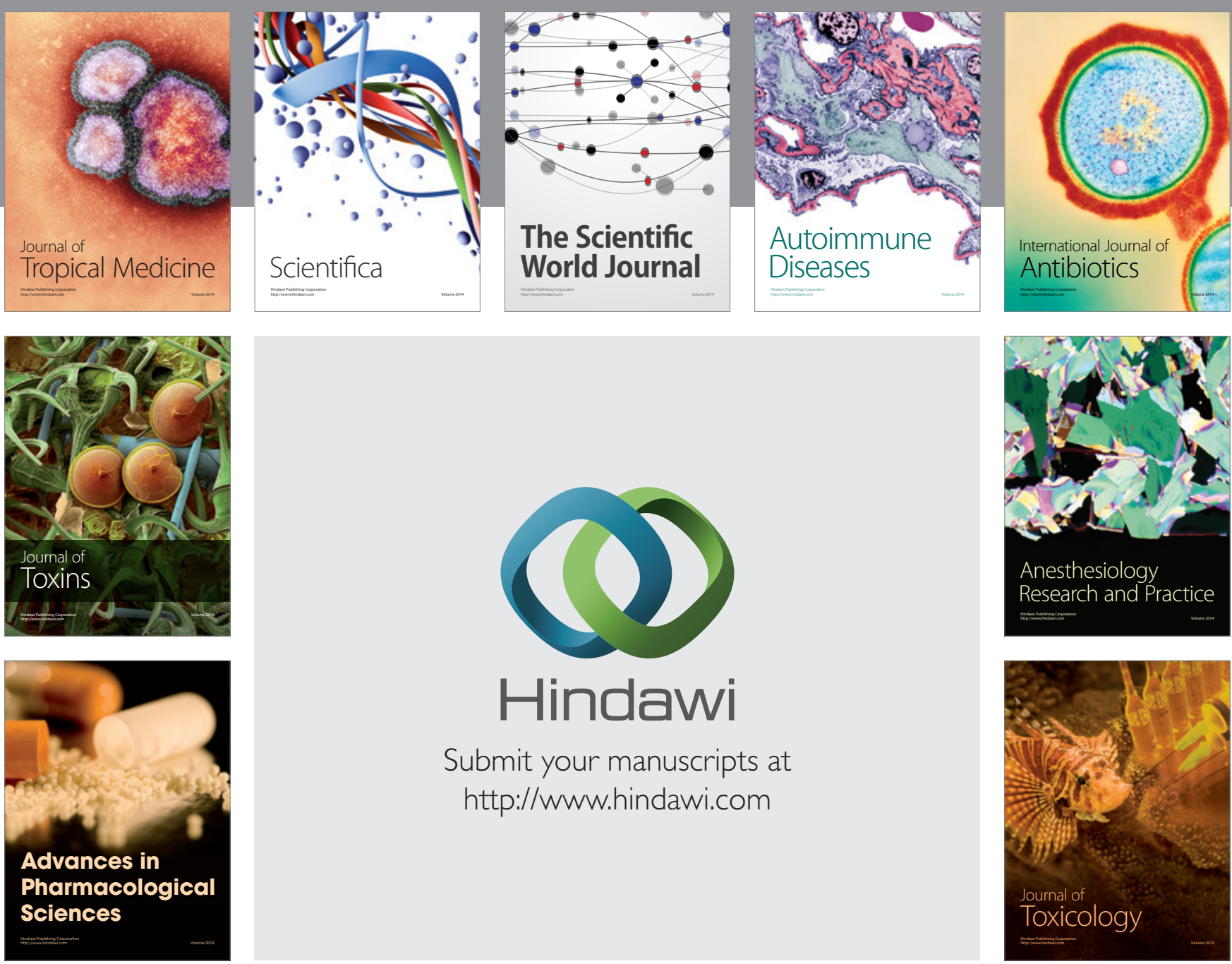

\section{Hindawi}

Submit your manuscripts at

http://www.hindawi.com
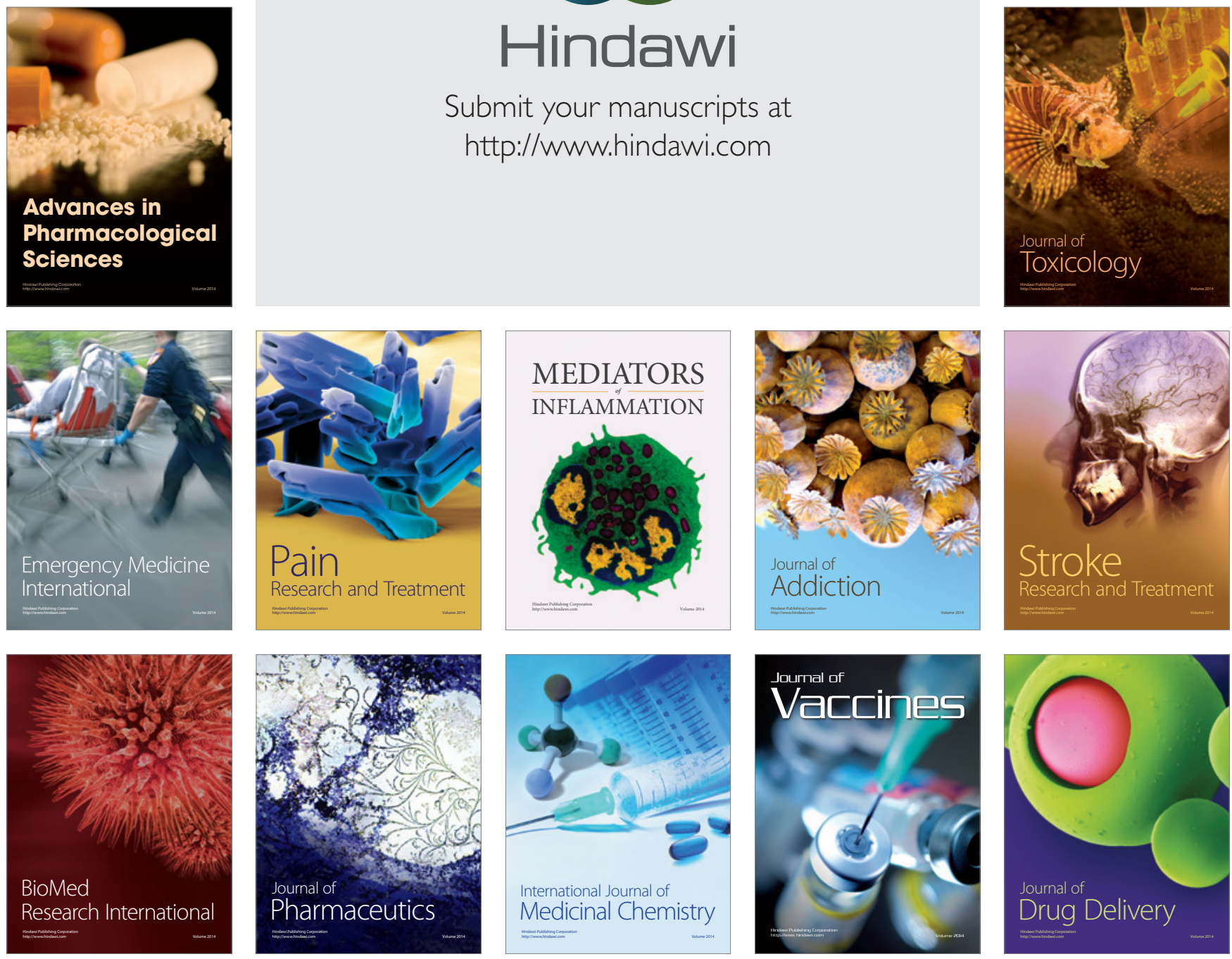